\title{
Effects of Changes to Hospitalist Admitter Staffing on Hospitalist Perception of Workload
}

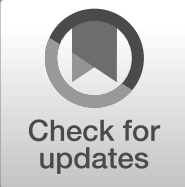

J Gen Intern Med 36(8):2488-9

DOI: $10.1007 / \mathrm{s} 11606-020-05961-5$

(C) Society of General Internal Medicine 2020

\section{INTRODUCTION}

Staffing models vary across hospital groups for many reasons, one of which is to balance workforce with anticipated workload. Excessive workload may contribute to errors and adverse events. ${ }^{1}$ Sustained periods of excessive workload may contribute to increased cognitive stress, frustration, ${ }^{2-4}$ and subsequently burnout. $^{5}$

Hospital admissions follow a diurnal pattern, increasing in the late afternoon. Many practices, including ours, employ afternoon swing shifts to address the admissions increase. In preparation for expanded bed coverage, our hospitalist group analyzed admitting capacity relative to expected volume. We desired to measure and improve the absolute and experienced workload of the admitting hospitalists.

\section{METHODS}

We conducted a prospective pre-post study of weekday nonteaching hospitalists admitting general medical patients between 16 May 2018 and 15 September 2018. Bed expansion to 135 dedicated hospitalist non-teaching beds from 117 occurred on 16 July 2018. We targeted 3:00 PM-7:00 PM, when admissions often exceeded our weekday admitting capacity. We increased the number of admitting hospitalists from 3 to 4 and adjusted shift times to ensure optimal coverage. We defined admitting capacity as admitter-hours (one admitter working $1 \mathrm{~h}$ is one admitter-hour).

We measured perceived workload using the NASA Task Load Index (TLX), a validated survey used to gauge workload across 6 domains (Table 1). We calculated an overall unweighted score as has been done in prior research. ${ }^{6}$ Admitters were surveyed at 5:00 PM on weekdays, the crest of admitting time (presumably peak stress). Physician participants voluntarily completed the survey and returned it anonymously.

The primary outcome was hospitalist perception of workload. Secondary measures were admissions per admitter and per admitter-hour. Admitting physician characteristics (age,

Received April 22, 2020

Accepted June 4, 2020

Published online June 24, 2020 sex, time at our institution, time since residency, ethnicity) were collected and compared with Wilcoxon rank-sum and chi-square tests. TLX scores were compared using Student's $t$ test. Patient characteristics (age, sex, primary diagnosis, insurance status, and source of admission) were collected and compared using chi-square, Wilcoxon, and $t$ tests. Admissions per admitter-hour were compared using Wilcoxon rank-sum test. Admissions per admitter were compared using Student's $t$ test. Analyses were conducted using SAS version 9.4 (Cary, NC). Our study was approved by the Northwestern University Institutional Review Board.

\section{RESULTS}

Overall, 34 hospitalists completed surveys pre-change and 37 post. Hospitalist characteristics were similar between groups. Hospitalist admitters submitted 52 of 86 distributed surveys (60\%) pre-change and 55 of 90 surveys (61\%) post. Postchange, hospitalist admitters reported lower overall workload $(10.9 \pm 1.2$ vs. $8.8 \pm 1.2 ; p=0.02)$. Improvements were noted in the domains of temporal demand $(12.9 \pm 1.4$ vs. $9.5 \pm 1.4$, $p=0.0007)$, effort $(13.0 \pm 1.1$ vs. $10.5 \pm 1.2, p=0.004)$, and frustration (11.3 \pm 1.4 vs. $7.6 \pm 1.1, p=0.0001)$.

Overall, 494 patients were admitted pre-change and 504 post. Patient characteristics were similar. Median admissions per admitter-hour decreased by $25 \%(1.00$ (IQR $0.67,1.33)$ vs 0.75 (IQR $0.42,1.25$ ), $p<0.001$ ). The number of admissions per admitter during the 3:00 PM-7:00 PM period decreased by $22 \%(4.21 \pm 0.35$ vs $3.28 \pm 0.27, p<0.0001)$.

\section{DISCUSSION}

We found changing staffing structure to target high-volume admission periods improved physicians' perception of workload. The most pronounced differences were in the temporal demand, effort, and frustration categories. The improvement in the perception of workload was likely due to reduced work stress by improving time pressures associated with admissions. The rate of new patients assigned to admitters can vary throughout an individual shift. When the number of new admissions exceeds the number of available admitters, a queue of patients develops. This sort of time pressure is a known contributor to work stress. In the post-change period, the median number of admissions per admitter-hour declined as 
Table 1 Comparison of NASA-TLX Surveys Pre- and Post-change to Admitter Staffing*

\begin{tabular}{|c|c|c|c|c|c|}
\hline \multirow[t]{2}{*}{ All } & \multicolumn{2}{|c|}{$\begin{array}{l}\text { Mean TLX } \\
\text { value } N=52\end{array}$} & \multicolumn{2}{|c|}{$\begin{array}{l}\text { Mean TLX } \\
\text { value } N=55\end{array}$} & \multirow[t]{2}{*}{$P$} \\
\hline & Pre & $95 \% \mathrm{CI}$ & Post & $95 \% \mathrm{CI}$ & \\
\hline Mental demand & 11.9 & $10.7-13.1$ & 10.1 & $8.9-11.3$ & 0.046 \\
\hline Physical demand & 7.6 & $6.4-8.8$ & 6.7 & $5.7-7.7$ & 0.261 \\
\hline Temporal demand & 12.9 & $11.5-14.3$ & 9.5 & $8.1-10.9$ & 0.001 \\
\hline Performance & 8.9 & $7.7-10.1$ & 8.3 & $6.9-9.7$ & 0.554 \\
\hline Effort & 13.0 & $11.9-14.1$ & 10.5 & $9.3-11.7$ & 0.004 \\
\hline Frustration & 11.3 & $9.9-12.7$ & 7.6 & $6.5-8.7$ & $<0.001$ \\
\hline Overall & 10.9 & $9.7-12.2$ & 8.8 & $7.6-10.0$ & 0.02 \\
\hline
\end{tabular}

*NASA-TLX National Aeronautics and Space Administration Task Load Index. Score range 0-20

physicians were better able to distribute and accommodate fluctuations in workload.

Our study has several limitations. First, our study was conducted at a single academic medical center. Second, we did not directly measure work performance, burnout, or patient outcomes. Third, to encourage honest responses, surveys were not identified at the time of completion and we could not conduct paired analyses.

We found that a staffing change that better matched the number of admitting hospitalists to the expected number of admissions improved physician perception of workload. These findings are important because excessive workload may impair work performance and contribute to physician burnout. Future research should evaluate whether favorable changes in workload are associated with improvements in physician performance, burnout, and patient outcomes.

Ajay Bhasin, $M D^{1}$

G. Randy Smith, MD, MS, FRCP(Edin), SFHM ${ }^{1}$

Ashish Gupta, $M D^{1}$

Shuhan Zhou, MPP ${ }^{1}$

Chen Yeh, $M S^{2}$
Jungwha Lee, $M P H^{2}$

Kevin J. O'Leary, $M D, M S^{1}$

${ }^{1}$ Department of Medicine, Division of Hospital Medicine, Northwestern University Feinberg

School of Medicine ,

Evanston, IL 60208, USA

${ }^{2}$ Department of Preventative Medicine, Northwestern University Feinberg School of Medicine,

Evanston, IL 60208, USA

Corresponding Author: Ajay Bhasin, MD; Department of Medicine, Division of Hospital Medicine, Northwestern University Feinberg School of Medicine Evanston, IL 60208, USA (e-mail: ajay.bhasin@nm.org).

\section{Compliance with Ethical Standards:}

Our study was approved by the Northwestern University Institutional Review Board.

Conflict of Interest: The authors declare that they do not have a conflict of interest.

\section{REFERENCES}

1. Weissman JS, Rothschild JM, Bendavid E et al. Hospital Workload and Adverse Events. Medical Care. 2007;45(5):448-455.

2. Michtalik HJ, Yeh H, Pronovost PJ, Brotman DJ. Impact of Attending Physician Workload on Patient Care: A Survey of Hospitalists. JAMA Intern Med. 2013;173(5):375-377.

3. Elliott DJ, Young RS, Brice J, Aguiar R, Kolm P. Effect of Hospitalist Workload on the Quality and Efficiency of Care. JAMA Intern Med. 2014; 174(5):786-793.

4. Michtalik HJ, Pronovost PJ, Marsteller JA, Spetz J, Brotman DJ. Developing a Model for Attending Physician Workload and Outcomes. JAMA Intern Med. 2013;173(11):1026-1028.

5. Dyrbye LN, Shanafelt TD, Sinsky CA et al. Burnout among health care professionals: a call to explore and address this underrecognized threat to safe, high-quality care. Available at: 2017;NAM.edu/perspectives; 1-11. Accessed Jan 10, 2020.

6. Hart SG. NASA-Task Load Index (NASA-TLX); 20 years later. Proceedings of the Human Factors and Ergonomics Society Annual Meeting. 2006;50(9):904-8.

Publisher's Note: Springer Nature remains neutral with regard to jurisdictional claims in published maps and institutional affiliations. 